\title{
A systematic review and meta-analysis of the effect of total parenteral nutrition and enteral nutrition on the prognosis of patients with acute pancreatitis
}

\author{
Mingshuang Liu ${ }^{1}$, Cong Gao ${ }^{2,3}$ \\ ${ }^{1}$ Emergency Department, The Affiliated Chengdu 363 Hospital of Southwest Medical University, Chengdu, China; ${ }^{2}$ Department of Emergency \\ Surgery, Sichuan Provincial People's Hospital, University of Electronic Science and Technology of China, Chengdu, China; ${ }^{3}$ Chinese Academy of \\ Sciences Sichuan Translational Medicine Research Hospital, Chengdu, China \\ Contributions: (I) Conception and design: Both authors; (II) Administrative support: Both authors; (III) Provision of study materials or patients: \\ Both authors; (IV) Collection and assembly of data: Both authors; (V) Data analysis and interpretation: Both authors; (VI) Manuscript writing: Both \\ authors; (VII) Final approval of manuscript: Both authors. \\ Correspondence to: Cong Gao. Sichuan Provincial People's Hospital, University of Electronic Science and Technology of China, Chinese Academy of \\ Sciences Sichuan Translational Medicine Research Hospital, 32 West 2nd Section, 1st Ring Road, Chengdu 610072, China. Email: gao7475c@163.com.
}

Background Nutritional support is very important in the treatment of severe acute pancreatitis, this study aimed to investigate the effect of total parenteral nutrition (TPN) and enteral nutrition (TEN) on the prognosis of patients with acute pancreatitis.

Methods: The databases of PubMed, Embase, Cochrane Library, and Ovid were searched using the keywords acute pancreatitis, enteral nutrition, and parenteral nutrition to obtain the reports of randomized controlled trials (RCTs) published after 2000. After screening the articles according to the inclusion criteria, risk of bias of the included literatures was evaluated using the Cochrane Handbook for Systematic Reviews. The software RevMan 5.3.5 was used for analysis and the creation of a forest plot and funnel plot.

Results: A total of 488 literatures were preliminarily searched in this study, from which 10 articles were included into the final quantitative analysis, involving a total of 699 participants. A total of 6 literatures $(\mathrm{n}=329$ participants) reported the infection rate indicators. The obtained statistic value [odds ratio $(\mathrm{OR})=0.25,95 \%$ confidence interval (CI): 0.10 to 0.62 ] showed TEN had less infection rate that TPN $(\mathrm{P}=0.003)$. A total of 8 studies (654 participants) reported the incidence rate indicators of multiple organ failure rate indicator, the obtained statistic value ( $\mathrm{OR}=0.50,95 \% \mathrm{CI}: 0.24$ to 1.08 ) showed no statistical difference between TEN and TPN (P>0.05). A total of 7 studies (550 participants) reported the mortality indicators. The obtained statistic value $(\mathrm{OR}=0.59,95 \% \mathrm{CI}: 0.37$ to 0.94$)$ showed TEN had less mortality than TPN $(\mathrm{P}=0.03)$. A total of 3 studies reported the length of hospital stay indicators. The obtained statistic value [mean difference (MD) $-4.18,95 \%$ CI: -5.07 to -3.30 ] showed the length of hospital stay for TEN was shorter that TPN $(\mathrm{P}<0.001)$. Discussion: Compared with TPN, TEN can reduce the incidence of infection, reduce the development of multiple organ failure, reduce mortality, and shorten the length of hospital stay in patients with severe acute pancreatitis (SAP). However, attention should be paid to prevent the occurrence of complications during the implementation of nutritional intervention.

Keywords: Total parenteral nutrition (TPN); enteral nutrition; acute pancreatitis; meta-analysis

Submitted Aug 13, 2021. Accepted for publication Sep 24, 2021.

doi: 10.21037/apm-21-2469

View this article at: https://dx.doi.org/10.21037/apm-21-2469 


\section{Introduction}

Severe acute pancreatitis (SAP) is a dangerous systemic wasting disease involving a systemic inflammatory response due to unexplained disordered pancreatic digestive enzyme secretion, the body enters a state of hypermetabolism and high protein decomposition. The patient's energy reserve is quickly consumed during the onset of SAP, resulting in multiple organ failure and endangering their life $(1,2)$. According to statistics (3), about $30 \%$ of patients are in a malnourished state at the onset of SAP. Malnutrition in turn slows wound healing, reduces immunity, and increases the risk of infection, which further aggravates the condition (4). Therefore, nutritional support is very important in the treatment of SAP. Some researchers have asserted that total parenteral nutrition (TPN) given during treatment can improve the nutritional status of patients without stimulating pancreatic juice secretion and allowing the pancreas to rest fully (5). However, other studies (6) have pointed out that parenteral nutrition support may present the risk of infection, and the incidence of hyperglycemia and hyper electrolyte imbalance syndrome. Numerous studies (7-9) have shown that total enteral nutrition (TEN) has more advantages in reducing the infection rate, reducing mortality, and reducing the rate of surgical intervention. In order to compare the effects of TEN and TPN and provide evidential support, we gathered recent evidence-based medical studies for meta-analysis. We present the following article in accordance with the PRISMA reporting checklist (available at https://dx.doi.org/10.21037/apm-21-2469).

\section{Methods}

\section{Search database and strategy}

We searched the databases of PubMed, Embase, Cochrane Library, and Ovid for randomized controlled trials (RCTs) published between January 2010 and August 2021 using the following keywords: acute pancreatitis, severe acute pancreatitis, pancreatitis, enteral nutrition, parenteral nutrition, EN, PN, TEN, and total parenteral.

\section{Criteria for inclusion}

The literature inclusion criteria were as follows: (I) participants: the patients included in the study had SAP, with an APACHE II score of more than 6 points; (II) after emergency intervention in the intensive care unit, participants were clearly divided into TEN group and
TPN group for nutritional intervention: TEN group could use nasogastric access (NG), or nasojejunal path (NJ), parenteral nutrition intervention involved regular injection of adequate nutrients via a central venous catheter; (III) the time of nutritional intervention was the same for both participant groups; (IV) the outcome measures included at least 1 of the infection rate, mortality, multiple organ failure rate, or length of hospital stay indicators. Infections included pancreatic infection and resulting pancreatic necrosis, sepsis, or systemic inflammatory response syndrome (SIRS). Multi-organ failure included respiratory failure, heart failure, and renal failure.

\section{Criteria for exclusion}

The literature exclusion criteria were as follows: (I) comparison of enteral nutrition and parenteral nutrition effect of non-acute pancreatitis, such as early nutrition intervention after stroke, or nutrition intervention after gastric or pancreaticoduodenectomy; (II) the intervention means were EN and PN mixed type; (III) investigation, case analysis, review, guidelines, systematic review, and so on of non-RCT; (IV) articles with the same study content in different databases; (V) missing indicators, or data could not be transformed and used (e.g., the median was used to express the hospitalization indicators, rather than the mean and standard deviation).

\section{Literature quality evaluation and bias analysis}

The Cochrane Handbook for Systematic Reviews (10) was used for literature quality evaluation and to assess the risk of bias of the included studies. The evaluation of "low risk", "unclear", and "high risk" was performed according to the random allocation method of the literature, whether the blind method was used, whether there was a hidden scheme, description of the phenomenon of loss to follow-up in the protocol, selective reporting bias, and other biases. If an article was evaluated as low risk in 6 aspects, it was judged as a level A study; if there was 1 or more "unclear" literatures, it was assessed as level B; if there was 1 or more "high risk" evaluation indicators, it was categorized as level C.

\section{Literature screening}

Database retrieval, de-duplication, preliminary screening, and full-text screening of the studies was performed by two researchers. The finally included literatures were subjected 
to the risk of bias assessment. A third researcher was invited to arbitrate if a conflict of opinion arose during this screening process.

\section{Data extraction}

Next, two researchers independently read the full texts, and extracted the following data: year and month of publication, number and age of participants in each group, patient Apache II score, intervention time, length of hospital stay, number of infections, number of deaths, and number of multiple organ failures. If the data were shown as percentages, it was converted into actual number of cases; if the outcome measures were expressed as median (range), they were discarded and only data expressed as mean and standard deviation were used.

\section{Statistical methods}

(I) The software RevMan 5.3.5 (Copenhagen: The Nordic Cochrane Center, The Cochrane Collaboration, 2014) was used for meta-analysis; (II) binary variables were statistically analyzed by Mantel-Haenszel statistical method, using odds ratio (OR) and $95 \%$ confidence interval (CI) reported statistics, with $\mathrm{P}<0.05$ considered statistically significant; continuous variables were statistically analyzed by inverse variance, using mean and 95\% CI reported statistics; every article reporting the variables was included in the data synthesis; (III) forest plot descriptive statistics were used for comparison; (IV) literature heterogeneity was analyzed by $\mathrm{I}^{2}$ analysis and $\mathrm{Q}$ test, $\mathrm{I}^{2}>50 \%$ or $\mathrm{P}<0.1$ indicated heterogeneity of the results, and the random effects model was used to obtain OR value, otherwise the fixed effects model was used to obtain OR value; (V) if heterogeneity between studies was indicated, a case-by-case exclusion method was used for sensitivity analysis; (VI) funnel plot was used to indicate publication bias.

\section{Results}

\section{Literature screening results}

In this study, 502 articles (PubMed, n=168; Embase, $\mathrm{n}=133$; Cochrane, $\mathrm{n}=126$; Ovid, $\mathrm{n}=75$ ) were preliminarily searched and 14 was excluded after duplicating check. The titles and abstracts were read, 126 articles were excluded, and the remaining 362 articles were read in more detail. After screening according to the inclusion and exclusion criteria, 10 literatures were included in the final quantitative analysis, as shown in Figure 1. There were a total of 699 patients in the study. Basic characteristics, intervention measures, and outcome measures of the included studies are shown in Table 1.

\section{Literature quality and bias evaluation}

In this analysis, the study by Doley et al. (12) only used odd and even numbers to generate random sequence, which had greater risk of bias. The rest did not see high risk items. The detailed risk of bias is shown in Table 2 .

\section{Meta-analysis results}

\section{Comparison of the effect of TEN and TPN on the incidence of infection in patients with SAP}

A total of 6 studies including 329 patients reported the infection rate indicators. The study by Doley et al. (12) had high risk of random sequence generation, which could have led to selection bias. The studies had statistical heterogeneity $\left(\mathrm{I}^{2}=58 \%, \mathrm{P}=0.04\right)$, thus the random effects model was used. The obtained statistic value was (OR $=0.25,95 \%$ CI: 0.10 to 0.62 ), the statistical effect value was $Z=2.97, P=0.003$, and the difference was statistically significant $(\mathrm{P}<0.05)$. Sensitivity analysis was performed by case-by-case exclusion method. After excluding the studies (12), there was no statistical heterogeneity between studies $\left(\mathrm{I}^{2}=0 \%, \mathrm{P}=0.88\right)$. The statistical effect size was $(\mathrm{OR}=0.16$, 95\% CI: 0.09 to 0.29 ), the statistical value was $Z=6.04$, $\mathrm{P}<0.001$, and the difference was statistically significant $(\mathrm{P}<0.05)$ (Figures 2,3).

\section{Comparison of the effect of TEN and TPN on the} incidence of multiple organ failure in patients with SAP A total of 8 studies involving 654 patients reported the incidence rate indicators of multiple organ failure, among which statistical heterogeneity was detected $\left(\mathrm{I}^{2}=52 \%, \mathrm{P}=0.04\right)$, thus the random effects model was used. the obtained statistic value was $(\mathrm{OR}=0.50,95 \% \mathrm{CI}$ : 0.24 to 1.08 ), the statistical effect value was $\mathrm{Z}=1.77, \mathrm{P}=0.08$, and the difference was not statistically significant $(\mathrm{P}>0.05)$ (Figure 4).

\section{Comparison of the effect of TEN and TPN on mortality in patients with SAP}

A total of 7 literatures involving 550 patients reported the mortality indicators, among which statistical homogeneity 
Identification of studies via databases and registers

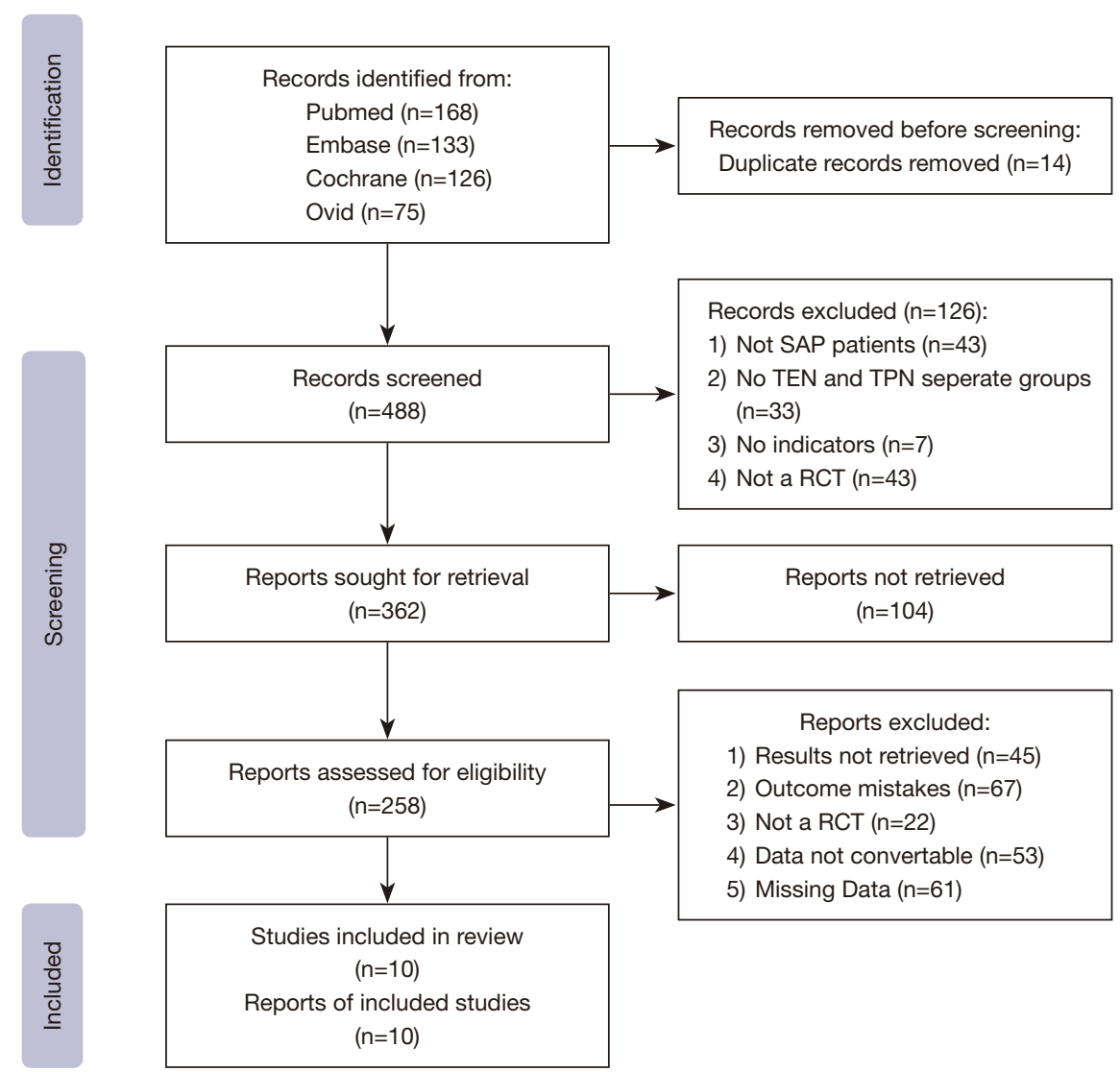

Figure 1 Search and selection flow diagram.

was detected $\left(I^{2}=0 \%, P=0.46\right)$, thus the fixed effects model was used. The obtained statistic value was ( $\mathrm{OR}=0.59,95 \%$ CI: 0.37 to 0.94 ), the statistical effect value was $Z=2.24$, $\mathrm{P}=0.03$, and the difference had statistical significance $(\mathrm{P}<0.05)$ (Figure 5).

\section{Comparison of the effect of TEN and TPN on the length of hospital stay in patients with SAP}

A total of 3 studies reported the length of hospital stay indicators, and these studies showed statistical homogeneity $\left(\mathrm{I}^{2}=0 \%, \mathrm{P}=0.54\right)$. Using the fixed effects model, the obtained statistic value was [mean difference $(\mathrm{MD})=-4.18,95 \% \mathrm{CI}$ : -5.07 to -3.30$]$, and the statistical effect value was $Z=9.28$, $\mathrm{P}<0.001$ (Figure 6).

\section{Sensitivity analysis and publication bias analysis}

The infection rate indicators were analyzed by piecemeal exclusion method, after exclude literature (12), the left studies showed no statistical heterogeneity, and the result was stable with both fixed effects mode and random effects mode. As the mortality rates indicator synthesis included more studies than the others, and the studies had no heterogeneity, a funnel plot was used to represent the publication bias analysis. The two groups of funnels were evenly distributed on both sides, suggesting that the possibility of publication bias was low, as shown in Figure 7 .

\section{Discussion}

Patients with SAP are in a state of high stress, high decomposition, and high metabolic inflammation, always accompanied by multiple organ failure and necrosis, with a high mortality rate. To date, statistics have shown that the mortality rate is between $30-40 \%$ (18). How to supplement body nutrition in time, reduce the risk of infection, and reduce mortality is a problem encountered 
Table 1 Basic characteristics, intervention measures, and outcome measures of included studies

\begin{tabular}{|c|c|c|c|c|c|c|c|c|c|}
\hline Author & Grouping & $\begin{array}{l}\text { Number of } \\
\text { participants }\end{array}$ & $\begin{array}{l}\text { Apache II } \\
\text { score }\end{array}$ & Age (years) & $\begin{array}{l}\text { Intervention } \\
\quad \text { time (d) }\end{array}$ & $\begin{array}{l}\text { Hospital stay } \\
\text { (d) }\end{array}$ & $\begin{array}{l}\text { Number of } \\
\text { Infections }\end{array}$ & $\begin{array}{l}\text { Number } \\
\text { of deaths }\end{array}$ & $\begin{array}{c}\text { Number of cases } \\
\text { with multiple } \\
\text { organ failure }\end{array}$ \\
\hline Wu et al. (11), 2010 & TPN & 54 & $14.0 \pm 2.1$ & $52.0 \pm 12.1$ & - & - & 39 & 23 & 44 \\
\hline Doley et al. (12), 2009 & TEN & 25 & - & $38.4 \pm 13.8$ & $3.52 \pm 0.92$ & $10.00 \pm 3.92$ & 16 & 5 & - \\
\hline \multirow[t]{2}{*}{ Stimac et al. (7), 2016} & TEN & 107 & $9.84 \pm 3.26$ & 69 [28-88] & 7 & - & - & 10 & 21 \\
\hline & TPN & 107 & $9.74 \pm 4.06$ & 72 [26-90] & 7 & - & - & 16 & 25 \\
\hline \multirow[t]{2}{*}{ Petrov et al. (8), 2006} & TEN & 35 & $12[10-14]$ & $51[42-67]$ & 7 & - & 7 & 2 & 7 \\
\hline & TPN & 34 & $12.5[11-16]$ & $52[41-70]$ & 7 & - & 16 & 12 & 17 \\
\hline \multirow[t]{2}{*}{ Oláh et al. (13), 2002} & TEN & 41 & - & 43.8 & 3 & - & - & 2 & 2 \\
\hline & TPN & 48 & - & 47.2 & 3 & - & - & 4 & 5 \\
\hline \multirow[t]{2}{*}{ Louie et al. (14), 2005} & TEN & 10 & $12.7 \pm 5.5$ & $65.3 \pm 18.3$ & 5 & - & 1 & - & - \\
\hline & TPN & 18 & $11.8 \pm 8.3$ & $60.8 \pm 17.0$ & 5 & - & 4 & - & - \\
\hline \multirow{2}{*}{$\begin{array}{l}\text { Abou-Assi et al. (15), } \\
2002\end{array}$} & EN & 26 & - & $48 \pm 3$ & $6.7 \pm 1.1$ & $14.2 \pm 1.9$ & 1 & 8 & 7 \\
\hline & PN & 27 & - & $50 \pm 3$ & $10.8 \pm 1.7$ & $18.4 \pm 1.9$ & 9 & 6 & 8 \\
\hline $\begin{array}{l}\text { Eckerwall et al. (16), } \\
2006\end{array}$ & TEN & 24 & 10 [8-13] & 71 [58-80] & 10 & - & - & 1 & 1 \\
\hline
\end{tabular}

- means not mentioned. TEN, total enteral nutrition; TPN, total parenteral nutrition; EN, enteral nutrition; PN, parenteral nutrition.

Table 2 Risk of bias based on Cochrane systematic review criteria for randomized interventions

\begin{tabular}{|c|c|c|c|c|c|c|c|}
\hline Study & $\begin{array}{l}\text { Generation of } \\
\text { random sequence }\end{array}$ & $\begin{array}{l}\text { Classification } \\
\text { hiding }\end{array}$ & $\begin{array}{l}\text { Blind } \\
\text { method }\end{array}$ & $\begin{array}{l}\text { Inadequate outcome } \\
\text { assessment }\end{array}$ & $\begin{array}{l}\text { Optional } \\
\text { reporting }\end{array}$ & Other Bias & Grade \\
\hline Wu et al. (11), 2010 & Low & Low & Low & Low & Low & Low & Class A \\
\hline Doley et al. (12), 2009 & High & Unclear & Unclear & Low & Low & Low & Grade C \\
\hline Stimac et al. (7), 2016 & Low & Low & Low & Unclear & Low & Low & Class B \\
\hline Oláh et al. (13), 2002 & Low & Unclear & Low & Low & Unclear & Low & Class B \\
\hline Louie et al. (14), 2005 & Unclear & Low & Low & Low & Low & Low & Class B \\
\hline Abou-Assi et al. (15), 2002 & Low & Low & Low & Low & Low & Low & Class A \\
\hline
\end{tabular}




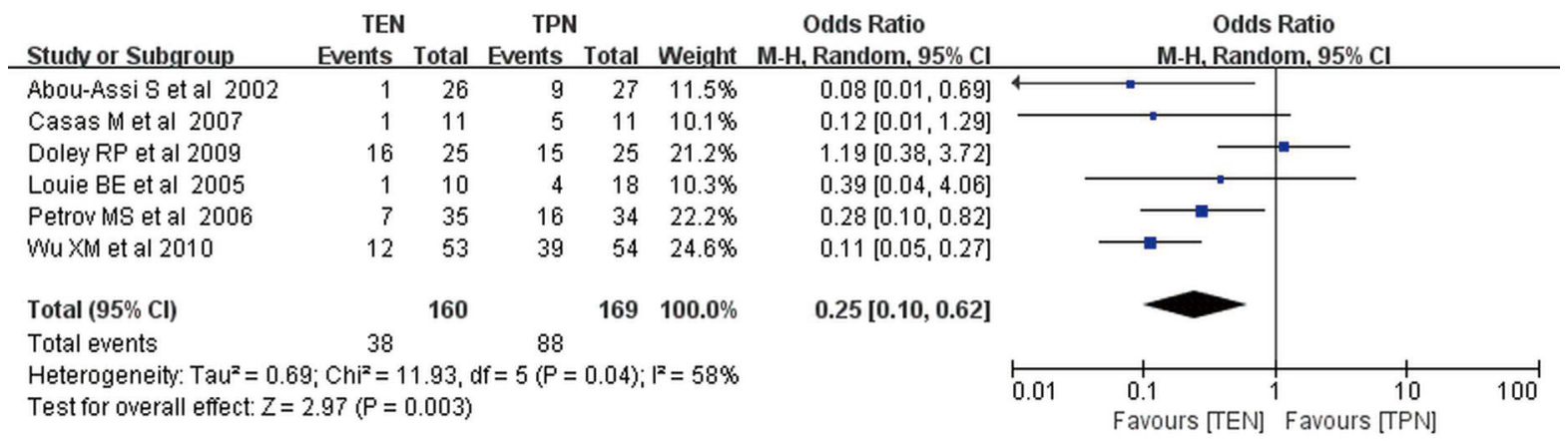

Figure 2 Comparison of the effect of TEN and TPN on the incidence of infection in patients with SAP. TEN, total enteral nutrition; TPN, total parenteral nutrition; CI, confidence interval; SAP, severe acute pancreatitis.

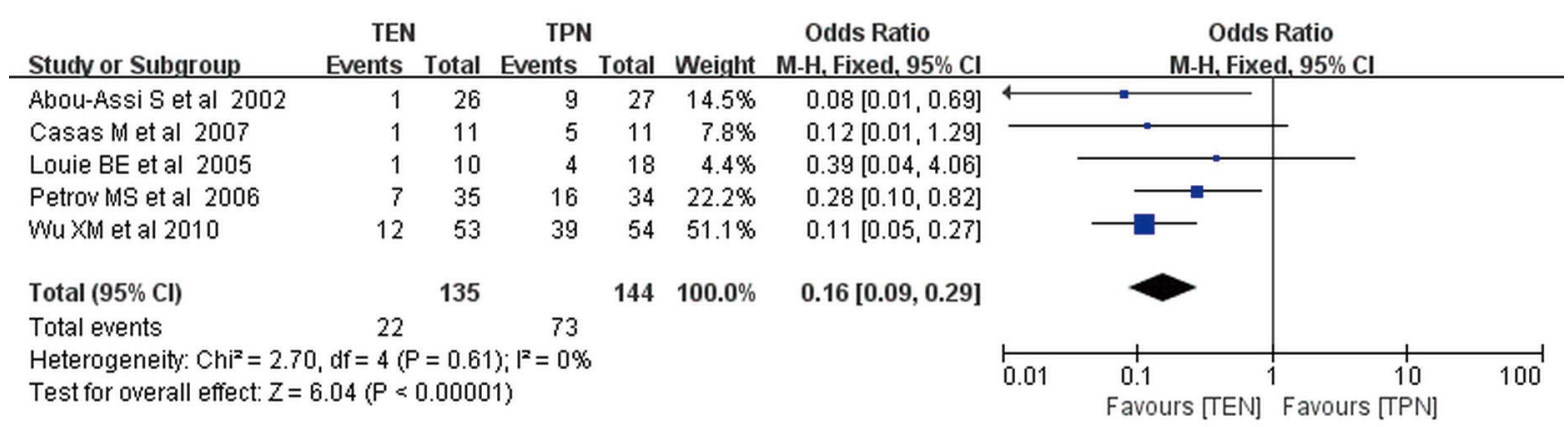

Figure 3 Sensitivity analysis: effect of TEN and TPN on the incidence of infection in patients with SAP. TEN, total enteral nutrition; TPN, total parenteral nutrition; CI, confidence interval; SAP, severe acute pancreatitis.

\begin{tabular}{|c|c|c|c|c|c|c|c|c|c|c|}
\hline Studv or Subgroup & $\begin{array}{l}\text { TEN } \\
\text { Events }\end{array}$ & Total & $\begin{array}{l}\text { TPN } \\
\text { Events }\end{array}$ & Total & Weight & $\begin{array}{c}\text { Odds Ratio } \\
\text { M-H, Random, } 95 \% \mathrm{Cl}\end{array}$ & & $\begin{array}{r}\text { Odds } \\
\text { M-H. Rando }\end{array}$ & $\begin{array}{l}\text { Ratio } \\
\text { om. } 95 \% \mathrm{Cl}\end{array}$ & \\
\hline Abou-Assi $S$ et al 2002 & 8 & 26 & 6 & 27 & $15.7 \%$ & $1.56[0.45,5.33]$ & & & & \\
\hline Casas M et al 2007 & 0 & 11 & 2 & 11 & $4.8 \%$ & $0.17[0.01,3.88]$ & & & & \\
\hline Doley RP et al 2009 & 5 & 25 & 4 & 25 & $13.5 \%$ & $1.31[0.31,5.60]$ & & & & \\
\hline Eckewwall GE et al 2006 & 1 & 24 & 0 & 26 & $4.5 \%$ & $3.38[0.13,87.11]$ & & & & \\
\hline Oláh A et al 2003 & 2 & 41 & 4 & 48 & $11.0 \%$ & $0.56[0.10,3.25]$ & & & & \\
\hline Petrov wS et al 2006 & 2 & 35 & 12 & 34 & $12.3 \%$ & $0.11[0.02,0.55]$ & & & & \\
\hline Stimac D et al 2016 & 10 & 107 & 16 & 107 & $20.1 \%$ & $0.59[0.25,1.36]$ & & & & \\
\hline Wu XM et al 2010 & 6 & 53 & 23 & 54 & $18.2 \%$ & $0.17[0.06,0.47]$ & & & & \\
\hline Total $(95 \% \mathrm{Cl})$ & & 322 & & 332 & $100.0 \%$ & $0.50[0.24,1.08]$ & & & & \\
\hline Total events & 34 & & 67 & & & & & & & \\
\hline \multicolumn{7}{|c|}{$\begin{array}{l}\text { Heterogeneity: } \text { Tau }^{2}=0.56 ; \mathrm{Chi}^{2}=14.71, \mathrm{df}=7(\mathrm{P}=0.04) ; \mathrm{I}^{2}=52 \% \\
\text { Test for overall effect: } Z=1.7 \mathrm{P}(\mathrm{P}=0.08)\end{array}$} & 0.01 & $\begin{array}{l}0.1 \\
\text { Favours [TEN] }\end{array}$ & $1 \frac{10}{\text { Favours [TPN] }}$ & 100 \\
\hline
\end{tabular}

Figure 4 Comparison of the effect of TEN and TPN on the incidence of multiple organ failure in patients with SAP. TEN, total enteral nutrition; TPN, total parenteral nutrition; CI, confidence interval; SAP, severe acute pancreatitis.

in clinical practice. The results of this study showed that compared with TPN, TEN could significantly reduce the infection rate $(\mathrm{OR}=0.16, \mathrm{Z}=6.04, \mathrm{P}<0.001)$, reduce mortality $(\mathrm{OR}=0.59, \mathrm{Z}=2.24, \mathrm{P}=0.03)$, shorten hospital stay $(\mathrm{MD}=-4.18, \mathrm{Z}=9.28, \mathrm{P}<0.001)$, and reduce multiple organ failure $(\mathrm{OR}=0.50, \mathrm{Z}=1.77, \mathrm{P}=0.08)$, which was consistent with the meta-analysis results of Marik et al. (19) and Li et al. (20). In the previous studies, the literatures included in the synthesis were either too old or with low quality, but in our study, more number of patients involving (up to 10 


\begin{tabular}{|c|c|c|c|c|c|c|c|c|c|c|}
\hline Studv or Subgroup & $\begin{array}{l}\text { TEN } \\
\text { Events }\end{array}$ & Total & $\begin{array}{l}\text { TPN } \\
\text { Events }\end{array}$ & Total & Weight & $\begin{array}{c}\text { Odds Ratio } \\
\text { M-H, Fixed, } 95 \% \mathrm{Cl}\end{array}$ & \multicolumn{4}{|c|}{$\begin{array}{c}\text { Odds Ratio } \\
\text { M-H, Fixed, } 95 \% \mathrm{Cl}\end{array}$} \\
\hline Abou-Assi S et al 2002 & 7 & 26 & 8 & 27 & $12.1 \%$ & $0.88[0.26,2.90]$ & & & & \\
\hline Casas M et al 2007 & 0 & 11 & 2 & 11 & $5.1 \%$ & $0.17[0.01,3.88]$ & & & & \\
\hline Eckerwall GE et al 2006 & 1 & 24 & 1 & 26 & $1.9 \%$ & $1.09[0.06,18.40]$ & & & & \\
\hline Oláh A et al 2003 & 2 & 41 & 5 & 48 & $9.3 \%$ & $0.44[0.08,2.40]$ & & & & \\
\hline Petrov MS et al 2006 & 7 & 35 & 17 & 34 & $29.2 \%$ & $0.25[0.09,0.73]$ & & & & \\
\hline Stimac D et al 2016 & 21 & 107 & 25 & 107 & $42.5 \%$ & $0.80[0.42,1.54]$ & & & & \\
\hline Wu XM et al 2010 & 11 & 53 & 44 & 0 & & Not estimable & & & & \\
\hline Total $(95 \% \mathrm{Cl})$ & & 297 & & 253 & $100.0 \%$ & $0.59[0.37,0.94]$ & & & & \\
\hline Total events & 49 & & 102 & & & & & & & \\
\hline $\begin{array}{l}\text { Heterogeneity: } \mathrm{Chi}^{2}=4.6 \\
\text { Test for overall effect: } Z=\end{array}$ & $\begin{array}{l}d f=5(P) \\
24(P=0 .\end{array}$ & $\begin{array}{l}=0.46) \\
.03)\end{array}$ & $F^{2}=0 \%$ & & & & 0.01 & $\begin{array}{c}0.1 \\
\text { Favours [TEN] }\end{array}$ & $\begin{array}{l}10 \\
\text { Favours [TPN] }\end{array}$ & $100^{\circ}$ \\
\hline
\end{tabular}

Figure 5 Comparison of the effect of TEN and TPN on mortality in patients with SAP. TEN, total enteral nutrition; TPN, total parenteral nutrition; CI, confidence interval; SAP, severe acute pancreatitis.

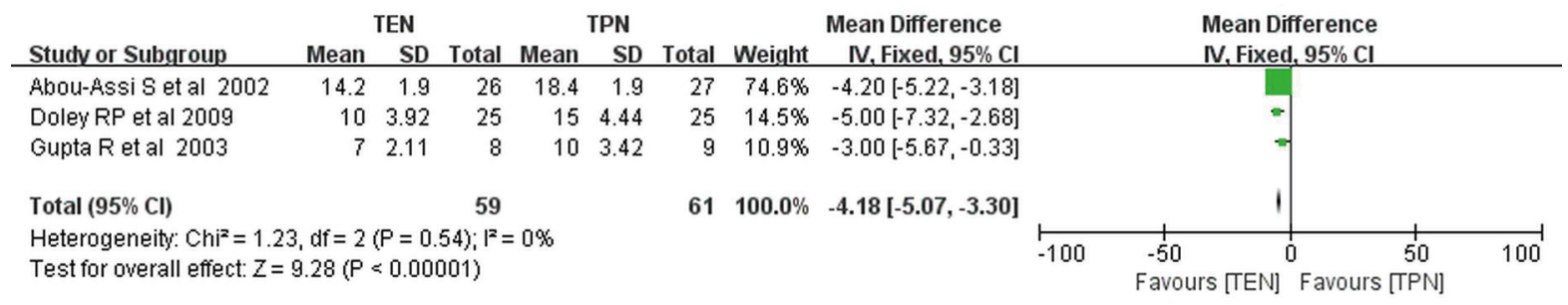

Figure 6 Comparison of the effect of TEN and TPN on the length of hospital stay in patients with SAP. TEN, total enteral nutrition; TPN, total parenteral nutrition; CI, confidence interval; SAP, severe acute pancreatitis.

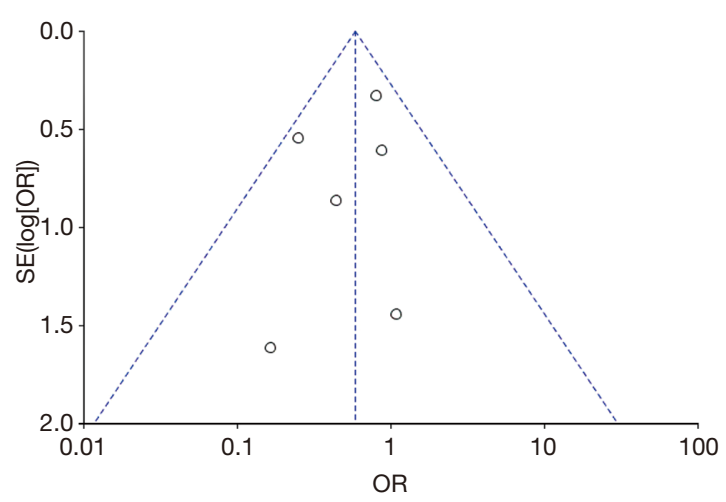

Figure 7 Funnel plot of the effect of TEN and TPN on mortality in patients with SAP. SE, standard error; OR, odds ratio; TEN, total enteral nutrition; TPN, total parenteral nutrition; SAP, severe acute pancreatitis.

literatures with 699 patients), and the literatures included were all with good quality [except literature (12) had risk of random sequence generation].

Study by Dutta et al. (21) has shown that intestinal bacterial translocation plays an important role in pancreatic infection in SAP. Complete EN can maintain the integrity of the intestinal barrier, prevent the invasion and proliferation of intestinal bacteria and toxins, and reduce the occurrence of pancreatic infection and sepsis. Study by Reintam Blaser et al. (22) has shown that TEN can reduce the levels of serum inflammatory factors [C-reactive protein (CRP), interleukin-8 (IL-8), tumor necrosis factor- $\alpha(\mathrm{TNF}-\alpha)$, reduce the progression of the disease to multiple organ failure, and therefore reduce mortality. In addition, several studies $(8,9)$ have shown that the rate of hyperglycemia and water and electrolyte imbalance in patients receiving TPN than in those receiving TEN, which may aggravate the process of organ failure. In a study conducted by Shen et al. (23), AP patients with enteral nutrition had lower serum endotoxin level and intestinal permeability than those with parenteral nutrition after two weeks of intervention, which reduced the translocation of toxin and heterogeneous bacteria and prevent inflammatory cells from releasing continually and excessively.

In this study, the complications of the two intervention methods were not statistically analyzed, because the focus of complications reported in each literature was not consistent, 
for example, a study (8) reported urinary tract infection, pneumonia, central venous infection, pipeline displacement, diarrhea, abdominal distension, hyperglycemia, and other complications in the two participant groups, while another study (15) only reported hyperglycemia, central venous pipeline infection, and other complications, so the overall complications of the research could not be uniformly analyzed. However, from the research reports, the common complications in the TEN group were abdominal distension, diarrhea, and gastrointestinal displacement or prolapse, while the common complications of TPN group were central venous infection and puncture site hematoma, and hyperglycemia. In a meta-analysis performed by Petrov et al. (24), 6 trials in which a total of 264 non-diabetic patients with acute pancreatitis included were treated with TEN \& TPN respectively, result showed that patients with TEN reduced the risk of hyperglycemia and gained better blood glucose control.

In this study, nasogastric tube was mostly used in the TEN group. In the study by Kumar et al. (25), nasogastric tube and nasojejunal route were compared, and it was found that both were safe and effective. It was recommended that nasojejunal route could be selected for nutritional support for patients after surgical intervention. Another study (26) showed that SAP patients with early enteral feeding (usually in $24 \mathrm{~h}$ after admission) would reducing the rate of infection or death, which is another intervention demonstrated to be clinical benefit in the management of patients with pancreatitis

Over the years there are many classifications and scores to diagnose and assess the severity of the SAP such as the APACHE Score, and the Ranson score, (27). Temporarily there are no directly pharmacotherapy for treating with SAP, strategies are targeted at preventing end-organ damage or reducing complications (28). The nutrition intervention stands important for the treating strategies. The parenteral nutrition doesn't need to place a nasal feeding tube, which avoid the uncomfortableness and without the concern for vomiting or aspiration, also the formulations could be adjusted daily, it has advantages especially for patients can't tolerate the enteral nutrition (29). But according to our study, it raised the infection rates and mortality, also, it's not cost efficient.

In this study, for the heterogeneity of literatures in the comparison of infection incidence, the case-bycase exclusion method was used for sensitivity analysis. After excluding certain studies (12), it was found that the remaining five studies had no statistical heterogeneity. The reason for the analysis may have been that the statistics of infection in the studies (12) included intrapancreatic infection and extrapancreatic infection (urinary tract infection, pulmonary infection), with mixed factors. The funnel plot showed that both sides were basically symmetrical, suggesting that the risk of publication bias was small. However, in this study, there were still some articles in which the blind method was not clear, the allocation concealment was unknown, and the random method produced method risks, which may have produced selection bias or implementation bias.

\section{Conclusions}

In conclusion, TEN can reduce the incidence of infection in patients with SAP, reduce development of the disease towards multiple organ failure, reduce mortality, shorten the length of hospital stay; but in the process of implementing nutritional intervention, attention should be paid to prevent the occurrence of complications. Due to the quality limitations of the articles included in this study, further in-depth exploration of topic is required including a larger number of RCTs.

\section{Acknowledgments}

Funding: None.

\section{Footnote}

Reporting Checklist: The authors have completed the PRISMA reporting checklist. Available at https://dx.doi. org/10.21037/apm-21-2469

Conflicts of Interest: Both authors have completed the ICMJE uniform disclosure form (available at https://dx.doi. org/10.21037/apm-21-2469). The authors have no conflicts of interest to declare.

Ethical Statement: The authors are accountable for all aspects of the work in ensuring that questions related to the accuracy or integrity of any part of the work are appropriately investigated and resolved.

Open Access Statement: This is an Open Access article distributed in accordance with the Creative Commons Attribution-NonCommercial-NoDerivs 4.0 International License (CC BY-NC-ND 4.0), which permits the non- 
commercial replication and distribution of the article with the strict proviso that no changes or edits are made and the original work is properly cited (including links to both the formal publication through the relevant DOI and the license). See: https://creativecommons.org/licenses/by-nc-nd/4.0/.

\section{References}

1. Italian Association for the Study of the Pancreas (AISP); Pezzilli R, Zerbi A, et al. Consensus guidelines on severe acute pancreatitis. Dig Liver Dis 2015;47:532-43.

2. Portelli M, Jones CD. Severe acute pancreatitis: pathogenesis, diagnosis and surgical management. Hepatobiliary Pancreat Dis Int 2017;16:155-9.

3. Greenberg JA, Hsu J, Bawazeer M, et al. Clinical practice guideline: management of acute pancreatitis. Can J Surg 2016;59:128-40.

4. Song J, Zhong Y, Lu X, et al. Enteral nutrition provided within 48 hours after admission in severe acute pancreatitis: A systematic review and meta-analysis. Medicine (Baltimore) 2018;97:e11871.

5. Lodewijkx PJ, Besselink MG, Witteman BJ, et al. Nutrition in acute pancreatitis: a critical review. Expert Rev Gastroenterol Hepatol 2016;10:571-80.

6. Oláh A, Romics L Jr. Enteral nutrition in acute pancreatitis: a review of the current evidence. World J Gastroenterol 2014;20:16123-31.

7. Stimac D, Poropat G, Hauser G, et al. Early nasojejunal tube feeding versus nil-by-mouth in acute pancreatitis: A randomized clinical trial. Pancreatology 2016;16:523-8.

8. Petrov MS, Kukosh MV, Emelyanov NV. A randomized controlled trial of enteral versus parenteral feeding in patients with predicted severe acute pancreatitis shows a significant reduction in mortality and in infected pancreatic complications with total enteral nutrition. Dig Surg 2006;23:336-44; discussion 344-5.

9. Gupta R, Patel K, Calder PC, et al. A randomised clinical trial to assess the effect of total enteral and total parenteral nutritional support on metabolic, inflammatory and oxidative markers in patients with predicted severe acute pancreatitis (APACHE II > or =6). Pancreatology 2003;3:406-13.

10. Cumpston M, Li T, Page MJ, et al. Updated guidance for trusted systematic reviews: a new edition of the Cochrane Handbook for Systematic Reviews of Interventions. Cochrane Database Syst Rev 2019;10:ED000142.

11. Wu XM, Ji KQ, Wang HY, et al. Total enteral nutrition in prevention of pancreatic necrotic infection in severe acute pancreatitis. Pancreas 2010;39:248-51.

12. Doley RP, Yadav TD, Wig JD, et al. Enteral nutrition in severe acute pancreatitis. JOP 2009;10:157-62.

13. Oláh A, Pardavi G, Belágyi T, et al. Early nasojejunal feeding in acute pancreatitis is associated with a lower complication rate. Nutrition 2002;18:259-62.

14. Louie BE, Noseworthy T, Hailey D, et al. 2004 MacLeanMueller prize enteral or parenteral nutrition for severe pancreatitis: a randomized controlled trial and health technology assessment. Can J Surg 2005;48:298-306.

15. Abou-Assi S, Craig K, O'Keefe SJ. Hypocaloric jejunal feeding is better than total parenteral nutrition in acute pancreatitis: results of a randomized comparative study. Am J Gastroenterol 2002;97:2255-62.

16. Eckerwall GE, Axelsson JB, Andersson RG. Early nasogastric feeding in predicted severe acute pancreatitis: A clinical, randomized study. Ann Surg 2006;244:959-65; discussion 965-7.

17. Casas M, Mora J, Fort E, et al. Total enteral nutrition vs. total parenteral nutrition in patients with severe acute pancreatitis. Rev Esp Enferm Dig 2007;99:264-9.

18. Ramanathan M, Aadam AA. Nutrition Management in Acute Pancreatitis. Nutr Clin Pract 2019;34 Suppl 1:S7S12.

19. Marik PE, Zaloga GP. Meta-analysis of parenteral nutrition versus enteral nutrition in patients with acute pancreatitis. BMJ 2004;328:1407.

20. Li W, Liu J, Zhao S, Li J. Safety and efficacy of total parenteral nutrition versus total enteral nutrition for patients with severe acute pancreatitis: a meta-analysis. J Int Med Res 2018;46:3948-58.

21. Dutta AK, Goel A, Kirubakaran R, et al. Nasogastric versus nasojejunal tube feeding for severe acute pancreatitis. Cochrane Database Syst Rev 2020;3:CD010582.

22. Reintam Blaser A, Starkopf J, Alhazzani W, et al. Early enteral nutrition in critically ill patients: ESICM clinical practice guidelines. Intensive Care Med 2017;43:380-98.

23. Shen QX, Xu GX, Shen MH. Effect of early enteral nutrition $(\mathrm{EN})$ on endotoxin in serum and intestinal permeability in patients with severe acute pancreatitis. Eur Rev Med Pharmacol Sci 2017;21:2764-8.

24. Petrov MS, Zagainov VE. Influence of enteral versus parenteral nutrition on blood glucose control in acute pancreatitis: a systematic review. Clin Nutr 2007;26:514-23.

25. Kumar A, Singh N, Prakash S, et al. Early enteral nutrition in severe acute pancreatitis: a prospective randomized controlled trial comparing nasojejunal and nasogastric routes. J Clin Gastroenterol 2006;40:431-4. 
26. Bakker OJ, van Brunschot S, van Santvoort HC, et al. Early versus on-demand nasoenteric tube feeding in acute pancreatitis. N Engl J Med 2014;371:1983-93.

27. Cofaru FA, Nica S, FierbinȚeanu-Braticevici C. Assessment of severity of acute pancreatitis over time. Rom J Intern Med 2020;58:47-54.

28. Krishnan K. Nutritional management of acute pancreatitis. Curr Opin Gastroenterol 2017;33:102-6.

29. Bordejé Laguna L, Lorencio Cárdenas C, Acosta Escribano

Cite this article as: Liu M, Gao C. A systematic review and meta-analysis of the effect of total parenteral nutrition and enteral nutrition on the prognosis of patients with acute pancreatitis. Ann Palliat Med 2021;10(10):10779-10788. doi: 10.21037/apm-21-2469
J; Guidelines for specialized nutritional and metabolic support in the critically ill-patient. Update. Consensus of the Spanish Society of Intensive Care Medicine and Coronary Units-Spanish Society of Parenteral and Enteral Nutrition (SEMICYUC-SENPE): severe acute pancreatitis. Med Intensiva 2011;35 Suppl 1:33-37.

(English Language Editor: J. Jones) 